\title{
Satellite Technologies in Geoinformation Science: Introduction
}

\author{
TOMASZ NIEDZIELSKI ${ }^{1}$
}

Rapid progress in geoinformation science, broadly understood as a variety of geospatial techniques and their research applications, is associated with increasing demand for spatial data. This does not only concern growing needs for new types of spatial information to be processed and interpreted, but also puts an emphasis on high spatial resolution and considerable sampling frequency. Traditional terrestrial techniques for collecting data in geodesy and cartography, although accurate and well-established, cannot serve the purpose of repetitive acquisition of high resolution data covering large areas. Frequent sampling, however, remains a fundamental feature of environmental monitoring projects. Given this context, geoinformation science has intrinsically been employing data and methods offered by satellite or aerial remote sensing and photogrammetry. Associated with this is a fundamental role of satellite technologies which either directly (satellite remote sensing) or indirectly (satellite navigation of various manned or unmanned aerial vehicles for remote sensing or photogrammetry) provide solutions for production of modern spatial data.

Geophysics does not only offer fundamentals for satellite and space geodetic techniques which are used to produce data which are routinely processed by various research teams working in geoinformation science, but also can adopt such data and the dedicated geospatial methods for carrying out geophysical analyses. The objective of this special issue of Pure and Applied Geophysics on "Satellite Technologies in Geoinformation Science" is to bring together

1 Department of Geoinformatics and Cartography, Institute of Geography and Regional Development, University of Wrocław, pl. Uniwersytecki 1, 50-137 Wrocław, Poland. E-mail: tomasz.niedzielski@uni.wroc.pl satellite technologies and their science applications performed with geoinformation tools, and such a combination is offered in a context of geophysical knowledge or potentials for geophysics itself.

The aforementioned multidisciplinary theme became a topic of the 21st Cartographic School on "Satellite technologies in GIS and cartography" held on 28-30 March 2012 in Wrocław, Poland. Since 2012 the scope of this regular meeting of cartographers has been shifted towards a new concept of presenting how geoinformation methods can serve as tools for solving fundamental research problems in Earth sciences. The review and research papers published in this special issue of Pure and Applied Geophysics relate to the selected presentations given at the 21st Cartographic School.

Two papers focus on applications of satellite technologies in geodynamics. Bosy (this issue) offers a general review paper on the contribution of satellite and space geodetic techniques to build the global International Terrestrial Reference System (ITRS) and the regional and national European Terrestrial Reference System 89 (ETRS89). Bogusz et al. (this issue) present a comparative analysis of numerous interpolation methods which aims to find an optimal solution for deriving velocity fields of plate movements in Poland, based on data from permanent reference stations.

Four papers report scientific results on applications of satellite and airborne technologies in geomorphology. In their paper, Kasprzak and Traczyk (this issue) show a combination of light detection and ranging (LiDAR) and two-dimensional electrical resistivity tomography (ERT) to infer landform characteristics, in particular to reconstruct buried terrain morphology in the city of Wrocław, Poland. Szostak et al. (this issue) use airborne laser scanning (ALS) in combination with orthophoto images in 
order to evaluate changes of land use and quantify forest succession in the experimental area of Milicz District, SW Poland. Drzewiecki et al. (this issue) present the application of high-resolution RapidEye satellite images and the object-based image analysis (OBIA) to diagnose areas which are vulnerable to soil erosion, and the analysis covers a relatively big area of Małopolska Voivodeship in Poland. Kolecka and Kozak (this issue) focus on the global shuttle radar topography mission (SRTM) data, namely SRTM C-band and SRTM X-band digital elevation models (DEMs), and-compared with high-resolution DEMs for the Polish Tatra Mountains-provide objective and quantitative assessment of these SRTM products in the high mountains.

There are three research articles on applications of satellite and airborne technologies in meteorology and climatology. Walawender et al. (this issue) propose an approach to calculate land surface temperature (LST) using the images acquired by Landsat-7, Enhanced Thematic Mapper Plus (ETM+), and the investigation is carried out for the urban environment, i.e., the city of Kraków, Poland. Jancewicz (this issue) shows the application of Corine land cover (CLC) data to provide estimates of terrain roughness, which-along with DEMs, also based on satellite observations-is subsequently used for modelling wind fields over the mountains. Windrelated problems are also considered in the paper by Suder and Szymanowski (this issue) who present that LiDAR data can be used in the process of calculating terrain roughness, and the presented approach-based on computation of aerodynamical properties of the city-helps to determine ventilation channels in urban environments, as shown for the city of Wrocław, Poland.

Two research papers present applications of satellite technologies in hydrology and limnology. Dimitriou et al. (this issue) investigate groundwater pollution and water quality and show that Landsat normalized difference vegetation index (NDVI) data combined with field monitoring are suitable for pollution risk mapping, and their case study focuses on the Evros River, having contributing areas in Bulgaria, Turkey and Greece. The aim of the paper by Popielarczyk and Templin (this issue) is to acquire very accurate bottom topography of the Hańcza Lake,
Poland, having integrated satellite observations based on the global navigation satellite system (GNSS) with the hydroacoustic measurements.

Not only inland waters but also oceans may be surveyed and researched with the help of satellites, and, hence, two papers are dedicated to applications of satellite technologies in oceanography. In his review paper, Priede (this issue) exemplifies a role of remote sensing in biogeography, and provides an historical review of various techniques to collect information on selected characteristics of the oceans. Satellite altimetry remains one of the techniques which are used for producing global bathymetry grids, and such data may serve as valuable inputs for modelling numerous depth-related phenomena in marine environments, as shown by Wieczorek et al. (this issue) who targeted at the spatial distribution of biomass in the ocean.

Applications of satellite and airborne technologies in cartography are discussed in three research papers. Bělka and Voženílek (this issue) present a concept of the orthoimage map, based on combining orthophoto images with the associated symbol components, and they argue that such products may be useful in geophysical studies. Drachal and Dębowska (this issue) focus on a problem of design of a physical map of Europe using satellite-derived DEM (SRTM30) and satellite images from a moderate-resolution imaging spectroradiometer (MODIS), and a few experiments which led to optimal solutions are presented. An example of real-time cartography, with extensive use of satellite navigation and terrestrial laser scanning, is given by Buchroithner et al. (this issue) who discuss integration of the two techniques for designing a nocturnal mountain rescue system.

\section{Acknowledgments}

The Guest Editor wishes to take this opportunity to express sincere thanks to a few people and organisations. I am grateful to Dr Renata Dmowska, the Editor-in-Chief for topical issues and book reviews at Pure and Applied Geophysics, who kindly accepted the proposal of the special issue on "Satellite Technologies in Geoinformation Science" and she has been offering her advice over the entire editorial 
procedure. I also thank the team of Birkhäuser/ Springer Basel AG for professional technical support. I am indebted to members of the Scientific Organising Committee and Local Organising Committee of the 21st Cartographic School as well as its organisers and supporters: the University of Wrocław, Section for Cartography of Polish Geographical Society, and the Lower Silesian Marshal's Office with its Department of Geodesy and Cartography. I would also like to acknowledge Mr Robert Pajkert, Director of the aforementioned department and Land Surveyor of Lower Silesia, whose support brought recognition of the importance of the 21st Cartographic School. I wish to thank all contributors who decided to submit their work to this special issue, leading to its multidisciplinary character. Last but not least, I am grateful to all reviewers who evaluated the manuscripts and offered valuable remarks which led to significant improvements of the content.

Open Access This article is distributed under the terms of the Creative Commons Attribution License which permits any use, distribution, and reproduction in any medium, provided the original author(s) and the source are credited.

(Received October 29, 2013, accepted October 30, 2013, Published online January 12, 2014) 